Research Article

\title{
Protective Cerium-Based Layered Double Hydroxides Thin Films Developed on Anodized AA6082
}

\author{
Muhammad Ahsan Iqbal iD and Michele Fedel \\ Department of Industrial Engineering, University of Trento, Via Sommarive 9 Povo (TN), Trento, Italy \\ Correspondence should be addressed to Muhammad Ahsan Iqbal; muhammadahsan.iqbal@unitn.it and Michele Fedel; \\ michele.fedel@unitn.it
}

Received 29 January 2020; Revised 17 April 2020; Accepted 22 April 2020; Published 19 May 2020

Academic Editor: Antonio Caggiano

Copyright (C) 2020 Muhammad Ahsan Iqbal and Michele Fedel. This is an open access article distributed under the Creative Commons Attribution License, which permits unrestricted use, distribution, and reproduction in any medium, provided the original work is properly cited.

\begin{abstract}
In this work, CeMgAl-LDHs protective thin films were developed directly on the anodized aluminum surface, and on the "hot water-sealed" anodized aluminum specimens. The synthesized coatings were investigated by SEM-EDS and XRD and through long-term electrochemical impedance spectroscopy (EIS) spectra. The growth of CeMgAl-LDHs into/onto the micropores/defects of anodized film was found to significantly improve the LDH barrier properties with delaying coating degradation compared to LDHs developed on the "hot water-sealed" surface. The unmodified LDHs "without cerium addition" were also developed to compare the influence of cerium on the structural and electrochemical properties of LDHs. It is also noteworthy that LDHs grown on the anodized surface provided dense and finer growth, while the addition of cerium ions was found to exhibit influential higher long-term corrosion resistance properties after the $1200 \mathrm{~h}$ immersion period.
\end{abstract}

\section{Introduction}

Layered double hydroxides (LDHs) based coatings are a new class of smart coating systems, where enough corrosion resistance properties can be achieved due to (i) LDHs anion exchange mechanism/self-healing capability to inhibit the damaging effect of corrosion reactions [1-3] and (ii) LDH barrier properties which resist the interaction of corrosive species to the substrate [4-6]. Considering the first aspect, various corrosion inhibitors are introduced to provide efficient anticorrosion properties [7-10], where entrapment of corrosive species and release of inhibitors result in delaying the degradation process of coatings. To promote the barrier properties, the synthesis of LDHs on the anodized aluminum substrate can provide significant active and passive corrosion protection to obtain a compact coating system [11]. Conceptually, the LDH grown on the anodized surface may seal the micropores of the anodized surface (improved barrier properties), while LDH itself provides active protection via entrapment of aggressive species and through self-healing properties [12]. Moreover,
LDH preferentially grows on the entire surface of the anodic film including the bumpy areas and on the complicated surface providing a suitable approach to protect the aluminum alloys [13].

Recently, rare earth elements were found to have a significant inhibiting effect and are the object of considerable scientific interest [14], exhibiting nontoxic nature [15]. Among rare earth elements, cerium-based coatings attracted significant attention, specifically also in case of incorporation inside the LDH network [16]. However, due to the larger ionic radius of cerium, it is difficult to introduce it in layered double hydroxide structure [17]. There are few reports, where the introduction of cerium through the urea hydrolysis method inside the LDH framework $[18,19]$ or solgel approach is reported [20]. However, a detailed study is needed to understand the influence of cerium addition on the LDHs long-term protective properties and possible interaction with the anodized film. The complex evaluation of the inhibition efficiency showed that solutions of $\mathrm{Ce}(\mathrm{III})$ ammonium nitrate salt reveal better inhibitive ability compared with those of Ce(IV) ammonium nitrate one, at 
relatively similar conditions of concentration and exposure time [21, 22]. Herein, we synthesize the Ce-doped $\mathrm{MgAl}$ LDHs directly on the anodized aluminum surface, and longterm corrosion resistance properties are systematically discussed. The paper is composed of two main sections, the synthesis of cerium- based LDH on the "hot water-sealed" anodized surface and, secondly, the development of CeMgAl-LDH directly on the microporous anodized surface. The effect of both approaches on corrosion performance is compared with unmodified LDHs and the possible mechanism of cerium interaction with $\mathrm{LDH}$ is described.

\section{Experiment}

2.1. Synthesis of the Anodized Layer. An AA6082 (wt.\%; 0.50 iron, 0.6-1.2 magnesium, 0.70-1.30 silicon, 0.10 copper, 0.40-1.0 manganese, and balance aluminum) round extruded bar $\left(3.14 \mathrm{~cm}^{2}\right.$ surface area) was cut in $1 \mathrm{~cm}$ thick small cylinders. The circular surface was mechanically ground with $\mathrm{SiC}$ grit papers, i.e., 500, 1000, 2400, 4000, and immersed in $0.1 \mathrm{M} \mathrm{NaOH}$ solution for 1 minute, followed by $0.1 \mathrm{M} \mathrm{HNO}_{3}$ solution for five minutes, rinsed with distilled water after each step. The anodization process was carried out in $0.1 \mathrm{M}$ $\mathrm{H}_{2} \mathrm{SO}_{4}$ electrolyte at a constant voltage of $14 \mathrm{~V}$ for 30 minutes at room temperature. The stainless-steel plate was used as a cathode, while pretreated AA6082 specimen acted as the anode. The surface area of the cathode was about $50 \mathrm{~cm}^{2}$ and the distance between the electrodes about $5 \mathrm{~cm}$. After anodization, the specimens were divided into two groups: the first group was treated with "hot boiling water" for 20 minutes to seal the porous anodized structure and further was used to developed LDHs on it, and the other was immersed in the mixture solution of cerium and magnesium nitrates, which act as a building block to fabricate LDH film on/into the anodic surface.

\subsection{Synthesis Route of CeMgAl-LDH}

(a) To synthesize single step CeMgAl-LDH, both types of anodized surfaces (hot water sealed and open porous) were vertically immersed in $0.01 \mathrm{M}$ $\mathrm{Mg}\left(\mathrm{NO}_{3}\right)_{2} \cdot 6 \mathrm{H}_{2} \mathrm{O}, 0.001 \mathrm{CeNO}_{3} \cdot 6 \mathrm{H}_{2} \mathrm{O}$ and $0.06 \mathrm{M}$ $\mathrm{NH}_{4} \mathrm{NO}_{3}$ mixture solution at $80^{\circ} \mathrm{C}$ for $18 \mathrm{hr}$ at atmospheric conditions. The precipitation of $\mathrm{Ce}(\mathrm{OH})_{3}$ on the anodized surface at high $\mathrm{pH}$ is also a wellexplained phenomenon [19]. The $\mathrm{pH}$ of the solution was maintained at 10 with a dropwise addition of $\mathrm{NH}_{4} \mathrm{OH}$ solution. All the chemicals were purchased from Sigma Aldrich.

(b) For reference, without cerium, MgAl-LDHs were also developed on the above-mentioned anodized surfaces, at the same synthetic conditions $\left(80^{\circ} \mathrm{C}\right.$ $24 \mathrm{hr}-10 \mathrm{pH}$ ) with similar magnesium salt concentration $(0.01 \mathrm{M})$. The general schematic representation of $\mathrm{LDH}$ synthesis on the anodized surface is shown in Figure 1. For simplicity, Table 1 describes the general terms to use further for the developed specimens.

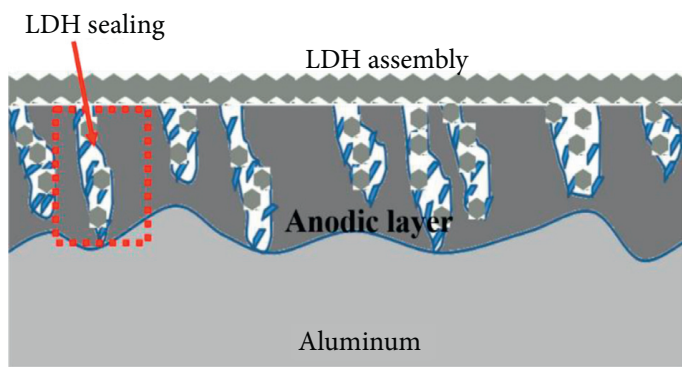

Figure 1: Schematic representation of LDH synthesis on the anodized surface.

\section{Characterization}

The structure and cross-section analysis of LDHs were characterized by SEM (JEOL JSM-IT300 equipped with an energy dispersive spectrometer (EDS)) including crosssectional imaging. XRD (X'Pert High Score diffractometer (Rigaku, Japan)) was performed using copper $K_{\alpha}$ emission source at $10 \mathrm{~mA}$ and $30 \mathrm{kV}$ conditions. The corrosion resistance properties were analyzed by electrochemical impedance spectroscopy (EIS) by using Parstat-2273 equipment with $0.1 \mathrm{M} \mathrm{NaCl}$ aqueous solution at open circuit potential $\left(\mathrm{E}_{\mathrm{OCP}}\right)$ at different exposure times, maximum 1200 hrs. A conventional three-electrode cell was used consisting of a $\mathrm{Ag} / \mathrm{AgCl}$ reference electrode $(+210 \mathrm{mV}$ vs SHE), a platinum ring as a counter electrode, and the investigated samples as a working electrode with an exposed area of $3.14 \mathrm{~cm}^{2}$. The electrochemical impedance spectroscopy (EIS) measurements were collected with an amplitude of $10 \mathrm{mV}$ at the frequency range from $0.01 \mathrm{~Hz}$ to $100 \mathrm{kHz}$. "Zsimpwin" software was used for EIS dataset fitting to further evaluate the coating film parameters and their effect on long-term stability.

\section{Results and Discussion}

XRD patterns of the developed LDHs films, with and without cerium addition, are presented in Figure 2. In all the specimens, well-resolved reflections of (003), (006), and (009) are observed clearly at around $11.8^{\circ}, 23^{\circ}$, and $34^{\circ}$, respectively, that are typical reflection peaks of LDHs. The "003" reflection peak corresponds to $0.75 \mathrm{~nm}$ basal spacing, which confirms presence of carbonates inside LDHs [23]. It is found that the incorporation of cerium ions in $\mathrm{LDH}$ structure did not make any dominant difference in $\mathrm{LDH}$ characteristics peaks with similar basal spacings, and thus we can assume that cerium ions are incorporated in the film in the amorphous form [9]. However, slight variation in peak intensities is observed on cerium addition which indicates a little variation of crystallinity on cerium addition into $\mathrm{LDH}$ lamellar layers. No dominant characteristics peaks of $\mathrm{CeO}_{2} /$ $\mathrm{Ce}_{2} \mathrm{O}_{3}$ are observed, thus suggesting the incorporation of cerium inside LDHs layers in the amorphous form [19].

The top view of SEM images (Figure 3) shows the anodized film before and after the LDH treatments. It is found that LDHs microcrystals grown on the anodized surface covered the entire substrates with a dense network of curvy 
TABLE 1: Developed LDHs specimens.

\begin{tabular}{lc}
\hline & Definition \\
\hline CeLDH & CeMgAl-LDH developed on anodized AA6082 surface \\
CeLDH-H & CeMgAl-LDH developed on "hot water-sealed" anodized AA6082 surface \\
LDH & MgAl-LDH developed on anodized AA6082 surface \\
LDH-H & MgAl-LDH developed on "hot water-sealed" anodized AA6082 surface \\
\hline
\end{tabular}

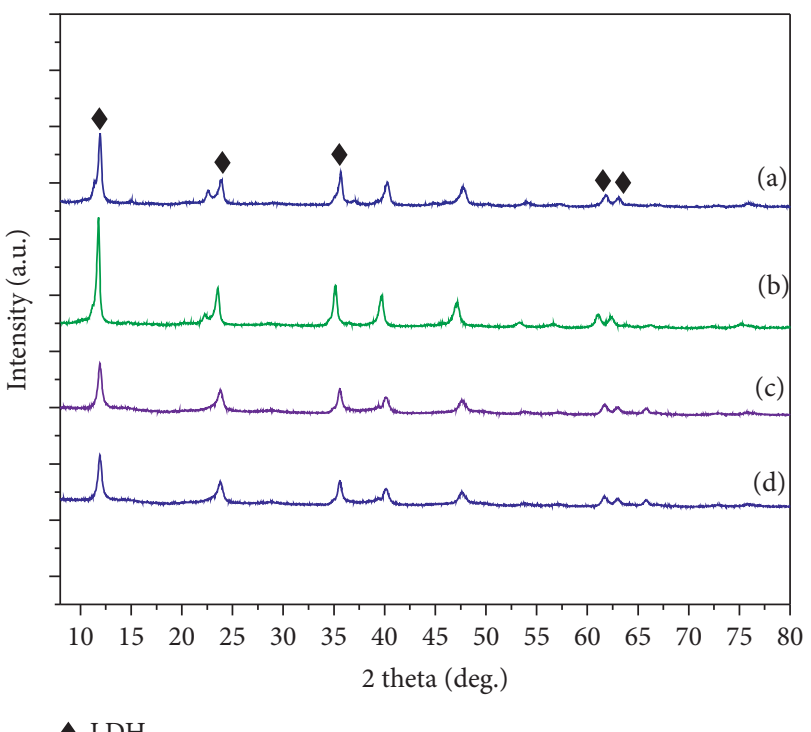

$\checkmark \mathrm{LDH}$

Figure 2: XRD spectra of LDHs films deposited on AA6082, (a) CeLDH, (b) LDH, (c) CeLDH-H, (d) LDH-H.

platelet LDHs structure (Figures 3(c) and 3(f)), compared to a less dense network of LDHs on bare AA6082 surface (Figure 3(b)). No clear difference was found of LDHs developed on open porous or/sealed anodized surface. However, the surface morphology of LDHs was affected by the doping of cerium addition where the reduction in the micropores size is observed. EDS quantitative results, in planer mode, are shown in Figure 4. The results described the higher amount of cerium in the case of $\mathrm{LDH}$ synthesis on the open porous anodized surface (Figure 4(d)), compared to the sealed anodized surface (Figure 4(c)). It may be due to the precipitation of more cerium content on open micropores porous aluminum oxide layer than the "hot watersealed" one. The elements $\mathrm{Mg}, \mathrm{Ce}, \mathrm{Al}, \mathrm{C}$, and $\mathrm{O}$ were found mainly to take part in the film formation. Moreover, the $\mathrm{Mg} / \mathrm{Ce}$ molar ratio was found to be 7.16 and 3.75 for the hot water sealed (CeLDH-H) and LDH precursors sealed films (CeLDH), respectively. The significant decrease of $\mathrm{Mg} / \mathrm{Ce}$ contents proposed the incorporation of effective cerium ions inside the CeLDH structure. The addition of cerium leads to decrease in the number of other elements in LDH surface as shown in EDS quantitatively analysis, which confirmed the presence of cerium ions in the LDHs network, either in amorphous form or/ and in the form of intermediate species $\mathrm{Ce}(\mathrm{OH})_{2}$ or $\mathrm{Ce}(\mathrm{OH})_{3}$ that can lead to the formation of $\mathrm{CeO}_{2}$ [24]. However, XRD analysis supports the incorporation of cerium in the amorphous form in the LDH network and no impure cerium ions phase is observed.
It is found that LDH film grows simultaneously "inward" and "outward" on the substrate, growth inward dense layer formed at $\mathrm{LDH} /$ substrate interface and outward porous network of LDHs formed at $\mathrm{LDH} /$ solution interface [25]. The dissolution of the aluminum oxide layer and interaction with the LDH precursors start LDH inward growth, while during that aluminum is oxidized to $\mathrm{Al}^{3+}$. Thus, thanks to the simultaneous presence of $\mathrm{Ce}^{3+}$ and $\mathrm{Mg}^{2+}$ ions, on interaction with $\mathrm{OH}^{-}$groups $\mathrm{Al}(\mathrm{OH})_{3}, \mathrm{Ce}(\mathrm{OH})_{3}$, and $\mathrm{Mg}(\mathrm{OH})_{2}$ are formed. In addition, cerium ions can diffuse inside LDH layers, resulting in the formation of MgAlCeLDH. In cross-sectional analysis (Figure 5), a two-layer structure is formed on the substrate, and anodic film starts partial dissolving on contact with the $\mathrm{LDH}$ precursors and results in the formation of LDH film on the anodic film and forms a compact structure [19]. It is reported that higher $\mathrm{pH}$ causes the hydrolysis of $\mathrm{Ce}^{3+}$, and this can promote the precipitation of $\mathrm{Ce}(\mathrm{OH})_{3}$ on the anodized surface. So, cerium participates in the sealing of micropores and in the building block of LDHs in the amorphous form [19]. The presence of $\mathrm{Ce}^{3+}$ ions may lead to partial oxidation to $\mathrm{Ce}^{4+}$ and can form mixed-species containing $\mathrm{CeO}_{2}, \mathrm{Ce}(\mathrm{OH})_{4}$ depending on $\mathrm{pH}$ of the surrounding solution [26]. The measured film thickness (anodization + LDH layer) of the developed specimens is shown in Figure 5(b), where "hot water-sealed" LDHs have shown comparatively a little higher film thickness than LDHs grown on microporous anodic film.

To understand the corrosion resistance behavior of modified and unmodified LDHs, electrochemical impedance spectroscopy spectra were collected in $0.1 \mathrm{M} \mathrm{NaCl}$ solution. The electrolyte has been selected in order to promote degradation of the LDH layer which allows us to monitor the potential inhibitive effect of $\mathrm{Ce}$ in the time scale investigated. The EIS spectra acquired after $1 \mathrm{~h}$ of immersion are reported in Figure 6. impedance modulus and phase plots are shown in order to better highlight the presence of the relaxation processes in the high-frequency range.

For general comparison among different developed LDH films, the impedance modulus in the low-frequency range can be employed for a rough estimation of the stability and corrosion resistance of the investigated samples [27]. Accordingly, as far as the impedance modulus at $0.01 \mathrm{~Hz}$ is concerned $\left(|Z|_{0.01}\right)$, the introduction of cerium in both forms (CeLDH, CeLDH-H) has shown initially an improvement compared to the reference samples. In particular, an increase of about 1.5 orders of magnitude of $|Z|_{0.01}$ is observed for cerium modified LDHs, compared to the unmodified LDHs (Figure 6(a)).

The phase plots (Figure 6(b)) of cerium modified and cerium-free LDHs both suggest the presence of two 


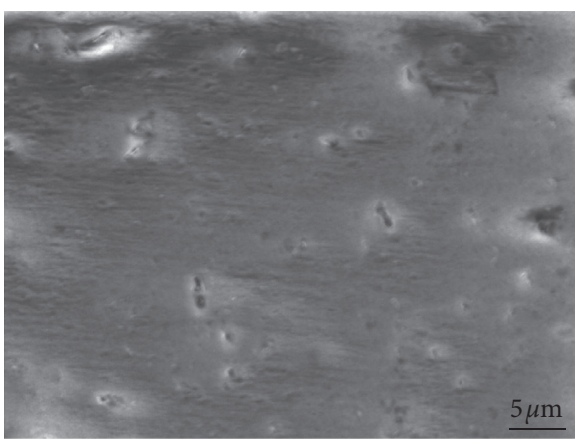

(a)

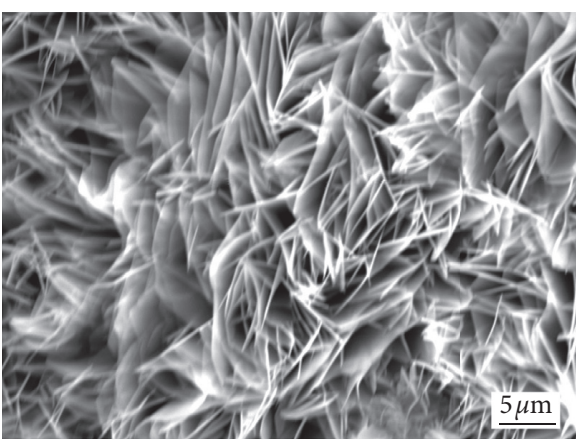

(c)

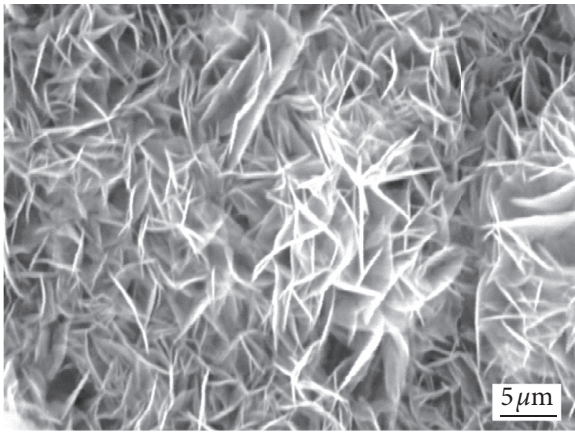

(e)

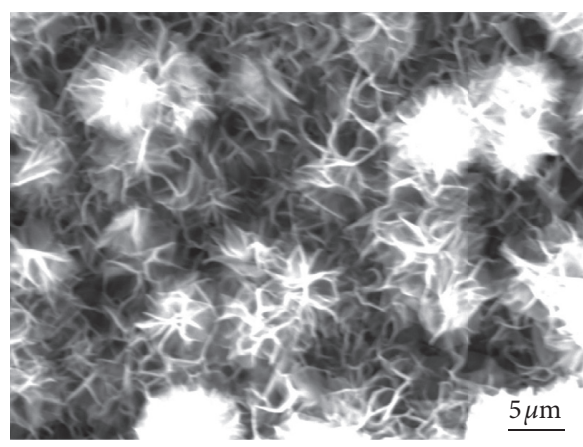

(b)

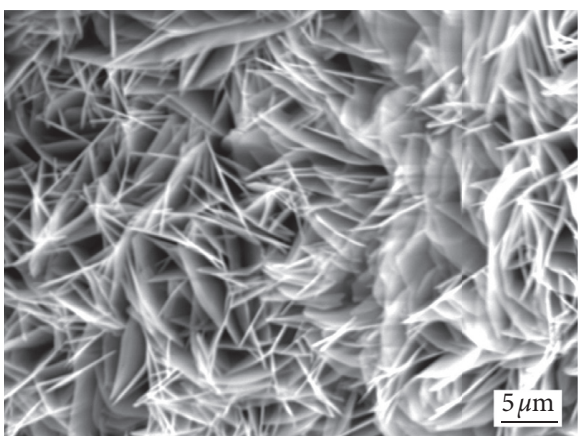

(d)

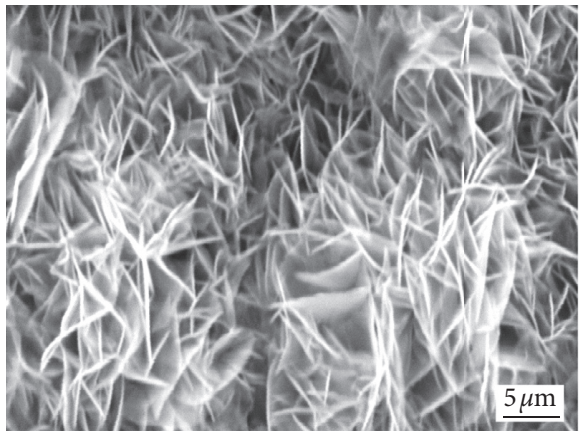

(f)

FIgure 3: SEM images of LDHs: (a) anodized surface, (b) LDH on bare AA6082 surface, (c) LDH, (d) LDH-H, (e) CeLDH, and (f) CeLDH-H.

relaxation processes. However, significant differences are observed: in the case of the Ce containing coatings, one time constant is located in the high-frequency range (around $10^{4} \mathrm{~Hz}$ ) and the other in the low-frequency range (around $10^{-1} \mathrm{~Hz}$ ), while for the $\mathrm{LDH}$ and $\mathrm{LDH}-\mathrm{H}$, the first time constant is shifted towards lower frequency range (around $10^{3} \mathrm{~Hz}$ ) and the second one towards the middle frequency range (around $10^{0}-10^{1} \mathrm{~Hz}$ ). To a first approximation, the high-medium frequency relaxation process is attributed to the outer porous surface layer and the other in medium-low frequency relaxation process is associated with the inner barrier layer. The time constant in the low-frequency range is believed to account also for the faradic process occurring at the substrate/film interface. A deeper discussion of the reasons underneath this attribution is provided at a later stage in the manuscript when the electrical equivalent circuits (e.e.c.) employed for the fitting are discussed. Considering the impedance plot in Figure 6(a), the CeMgAl-
LDH depicted higher impedance values in the middle-high frequency range, suggesting the better resistance of the upper layer as compared to unmodified LDH. As previously anticipated, higher impedance modulus values also in the low-frequency range have been observed for the Ce based LDHs, thus suggesting a reduced corrosion rate. The significantly enhanced corrosion resistance of Ce based LDHs can be explained by the following; (i) the passive protection of compact LDH layer and (ii) the presence of cerium in the $\mathrm{LDH}$ frame, which was found to provide protection by its inhibition action by dissolving from the LDHs structure, entering the solution and precipitating at the cathodic sites (mechanism is explained later in the manuscript). To better investigate the role of $\mathrm{Ce}$ in the $\mathrm{LDH}$ layers, the long-term stability of the developed coatings has been investigated upon exposure to the chloride containing media.

The impedance plots of the unmodified LDH after immersion for $1 \mathrm{~h}$ to $168 \mathrm{~h}$ are shown in Figures $7(\mathrm{a})$ and $7(\mathrm{~b})$. 


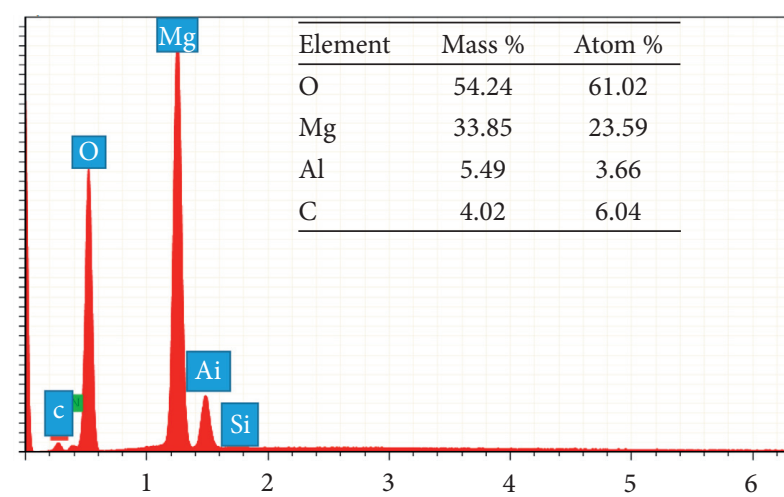

(a)

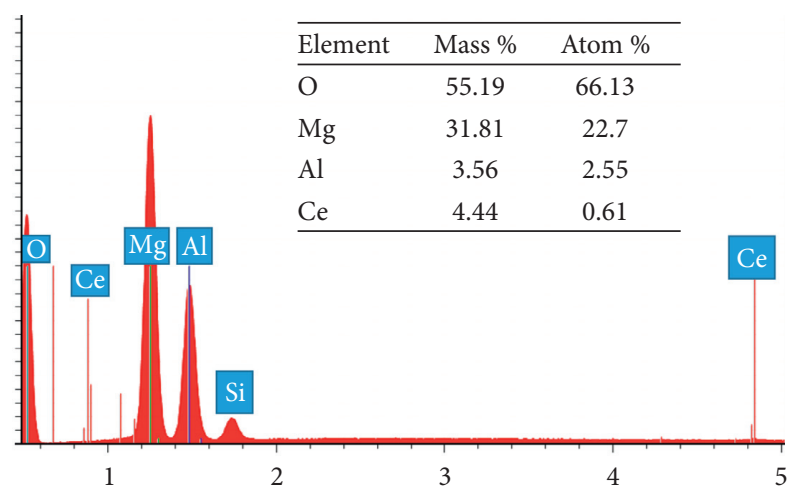

(c)

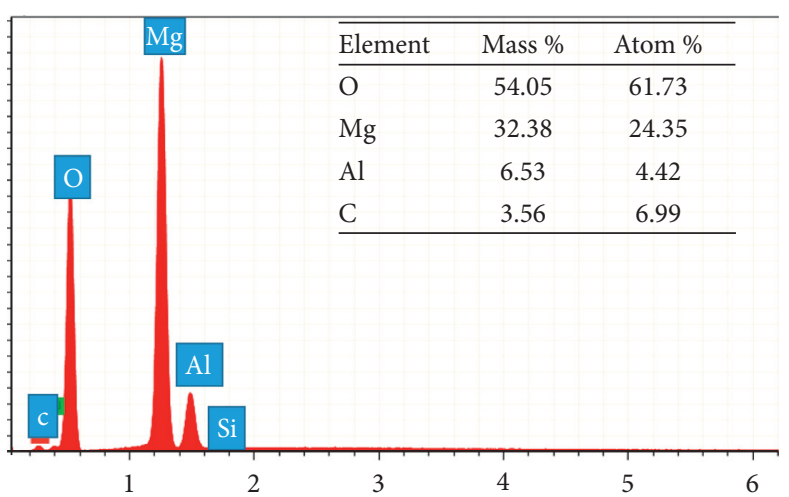

(b)

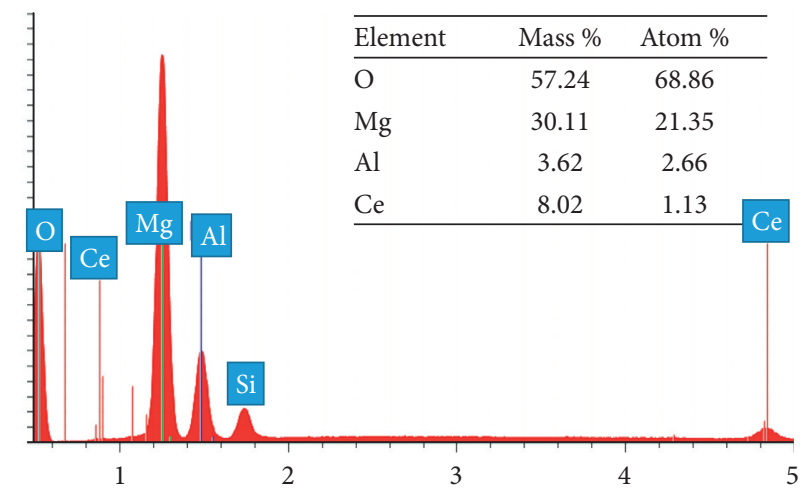

(d)

Figure 4: EDS spectra of the developed films and respective quantitative analysis: (a) LDH, (b) LDH-H, (c) CeLDH, and (d) CeLDH-H.

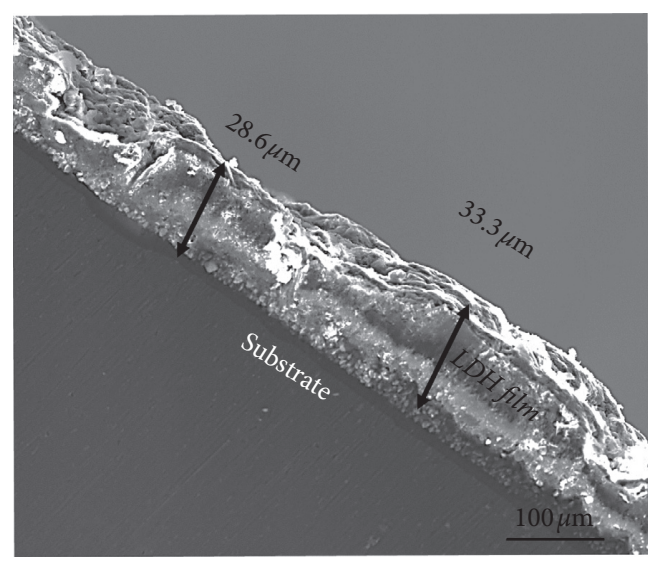

(a)

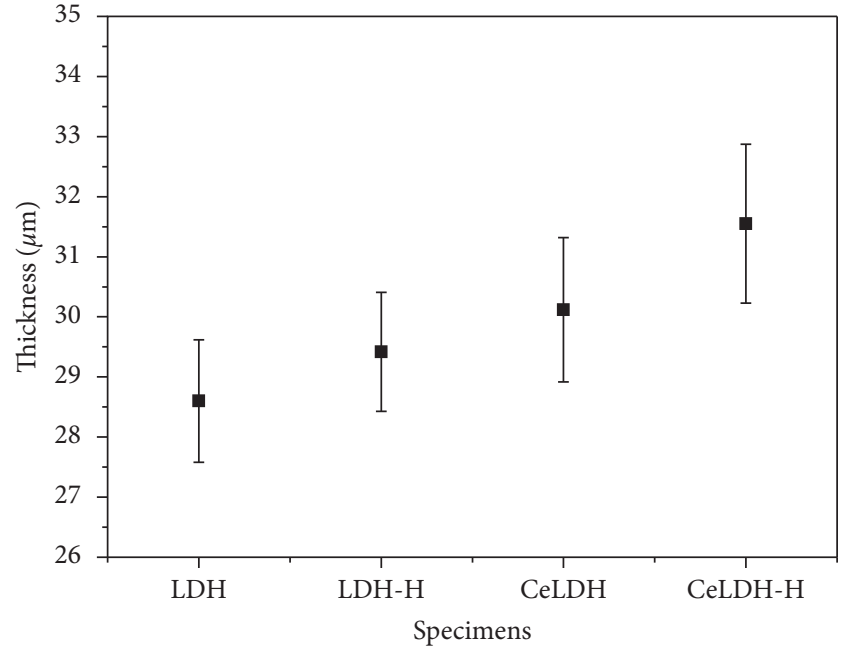

(b)

FIgure 5: (a) Cross-sectional analysis of CeLDH and (b) film thickness of developed specimens.

Samples LDH and LDH-H display impedance modulus at $0.01 \mathrm{~Hz}\left(|Z|_{0.01}\right)$ of about $10^{5} \Omega \cdot \mathrm{cm}^{2}$ after $1 \mathrm{~h}$ of immersion in the electrolyte. These layers do not show long-time stability: a decrease of $10^{4.5} \Omega \cdot \mathrm{cm}^{2}$ in $|Z|_{0.01}$ was observed after $168 \mathrm{~h}$ of immersion. The sealing effect is mainly observable, thanks to the $|Z|$ increase in the middle-high frequency range (it is the case) which can be attributed to an enhancement of the protection ability of the porous layer (which is sealed).

Modified Ce containing LDHs after various time intervals of immersion (from $1 \mathrm{~h}$ to $1200 \mathrm{~h}$ ) is shown in Figure 8 (including an enlarged version of the low-frequency impedance modulus in Figures $8(\mathrm{~b})$ and $8(\mathrm{~d})$ ). Initially, Ce modified $\mathrm{LDH}$, in both cases, has shown 


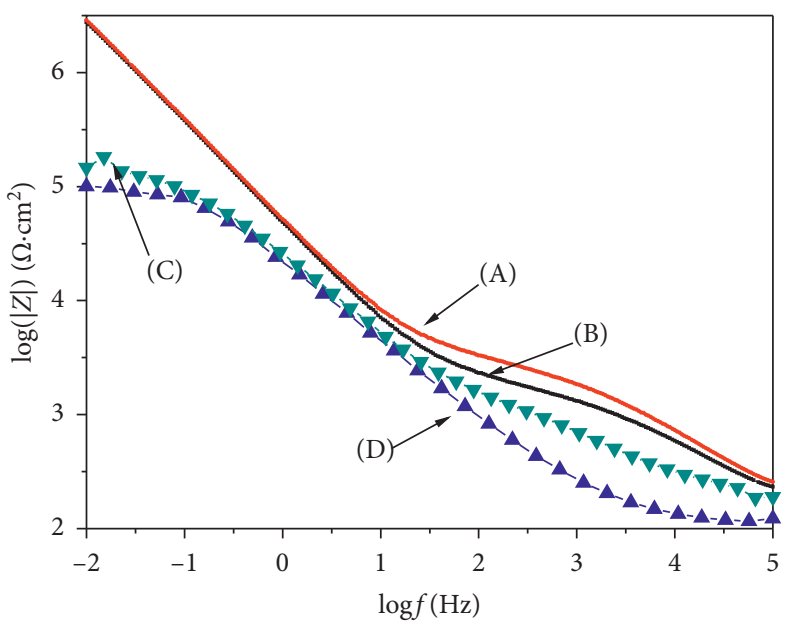

(a)

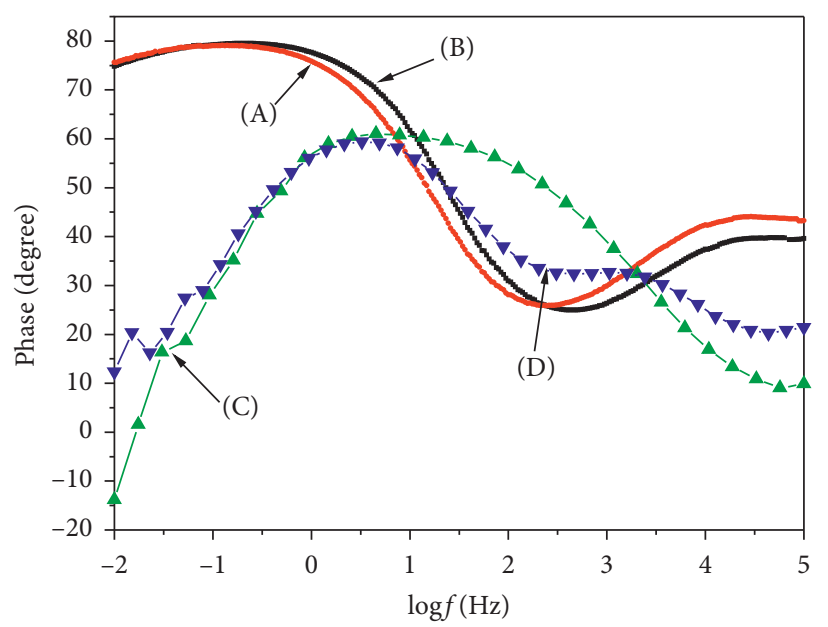

(b)

Figure 6: Impedance modulus. (a) Phase plots (b) after $1 \mathrm{~h}$ immersion in $0.1 \mathrm{M} \mathrm{NaCl}$ solution: (A) CeLDH, (B) CeLDH-H, (C) LDH, and (D) $\mathrm{LDH}-\mathrm{H}$.

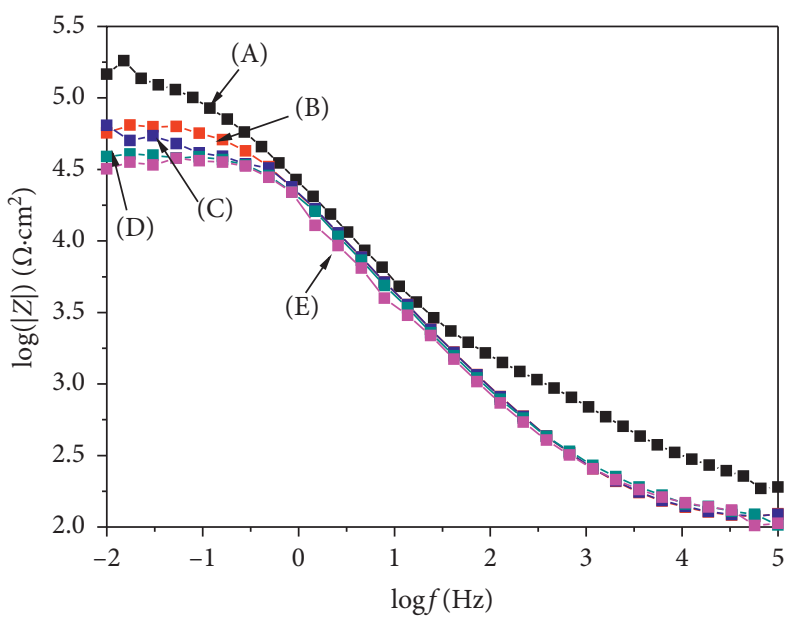

(a)

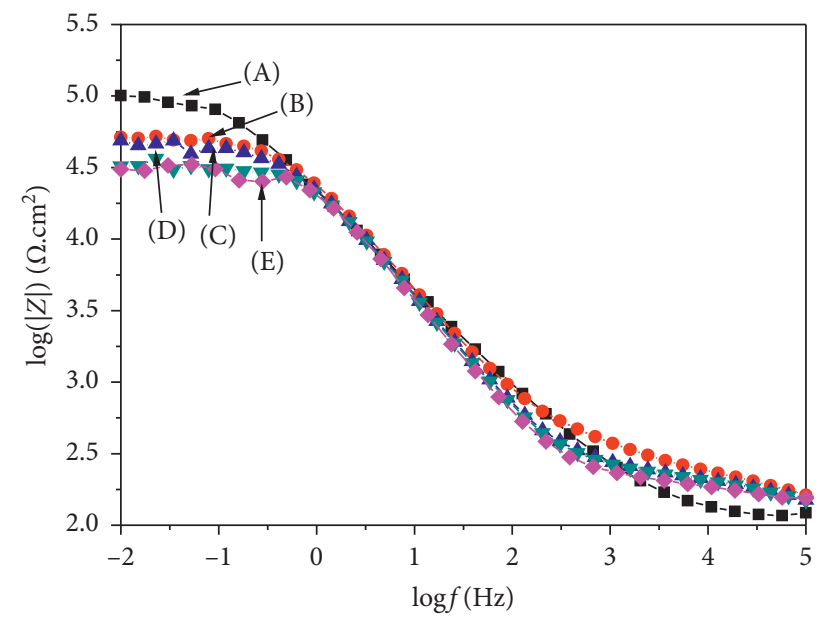

(b)

Figure 7: Impedance modulus plots. LDH (a) and LDH-H (b) for various immersion times: (A) $1 \mathrm{~h}$, (B) $24 \mathrm{~h}$, (C) $72 \mathrm{~h}$, (D) $120 \mathrm{~h}$, and (E) $168 \mathrm{~h}$.

almost the same $|Z|_{0.01}$ value $\sim 10^{6.5} \Omega \cdot \mathrm{cm}^{2}$ after $1 \mathrm{~h}$ of immersion. It is observed that $|Z|_{0.01}$ value reduced more rapidly from 1 to $72 \mathrm{~h}$ probably due to upper porous $\mathrm{LDH}$ layer, but on a later stage, a slower reduction rate is observed. On later immersion stages, $\mathrm{CeLDH}$ shows a lower decreasing rate of the low-frequency impedance compared to the CeLDH-H sample. The $|Z|_{0.01}$ value of CeLDHs reduced from $10^{6.5}$ to about $10^{5} \Omega \cdot \mathrm{cm}^{2}$ after $1200 \mathrm{hrs}$, while in case of CeLDH-H, it reduced from $10^{6.5}$ to about $10^{4.5} \Omega \cdot \mathrm{cm}^{2}$. This finding suggests higher stability of the CeLDH structure against the corrosive solution compared to the CeLDH-H.

To better compare the investigated samples, the $|Z|_{0.01}$ values of modified and unmodified LDHs as a function of immersion time are shown in Figure 9. The $|Z|_{0.01}$ values of
CeLDH are much higher than other developed LDH films throughout the whole immersion period. Moreover, a decrease in the declining rate is observed on exposure with long-term corrosive solutions. At the early stage of the corrosion mechanism, a relatively rapid decrease from $10^{6.5}$ to about $10^{5.5} \Omega \cdot \mathrm{cm}^{2}$ was observed for $\mathrm{CeLDH}$, while the decline rate was more severe for CeLDH-H, from $10^{6.5}$ to about $10^{5.2} \Omega \cdot \mathrm{cm}^{2}$. On the second stage of the exposure (after about $200 \mathrm{~h}$ ), a slower degradation process was observed for the $\mathrm{CeLDH}$ and $\mathrm{CeLDH}-\mathrm{H}$ samples. These findings suggest that, regardless of the difference between the Ce containing $\mathrm{LDH}$ coatings, the presence of $\mathrm{Ce}$ in the coatings improves the initial protection properties as well as the durability upon prolonged immersion in the electrolyte. This effect is believed to be related to the $\mathrm{LDH}$ development inside the 


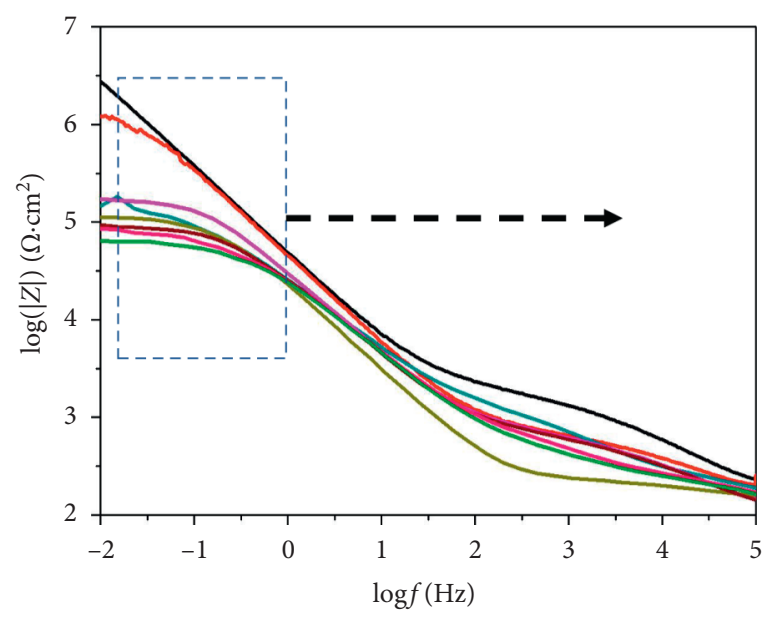

(a)

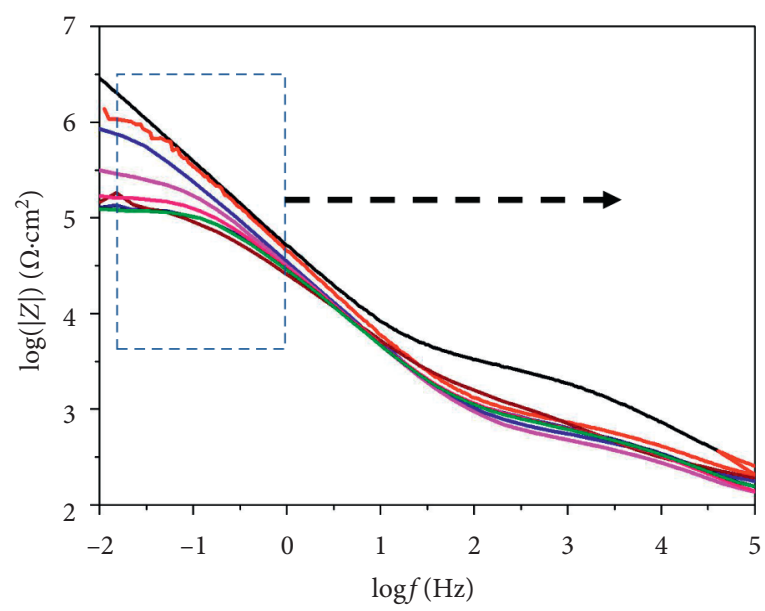

(c)

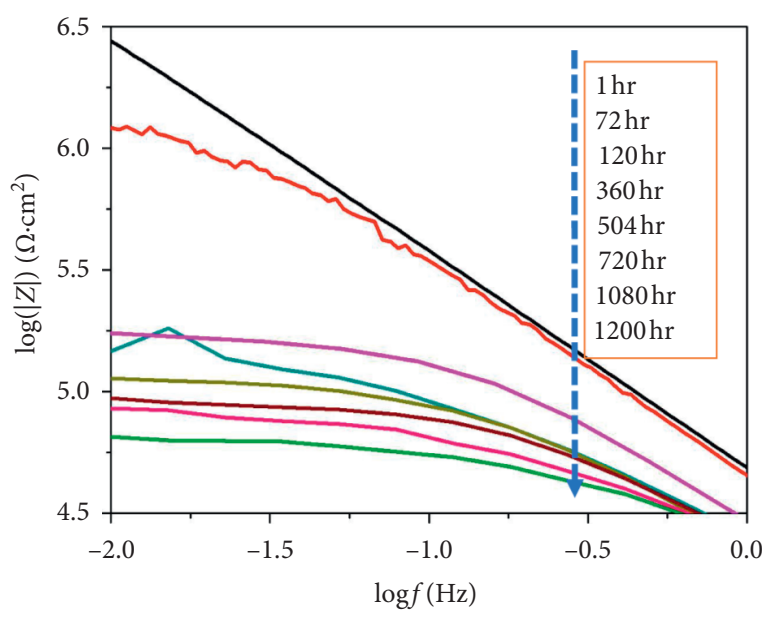

(b)

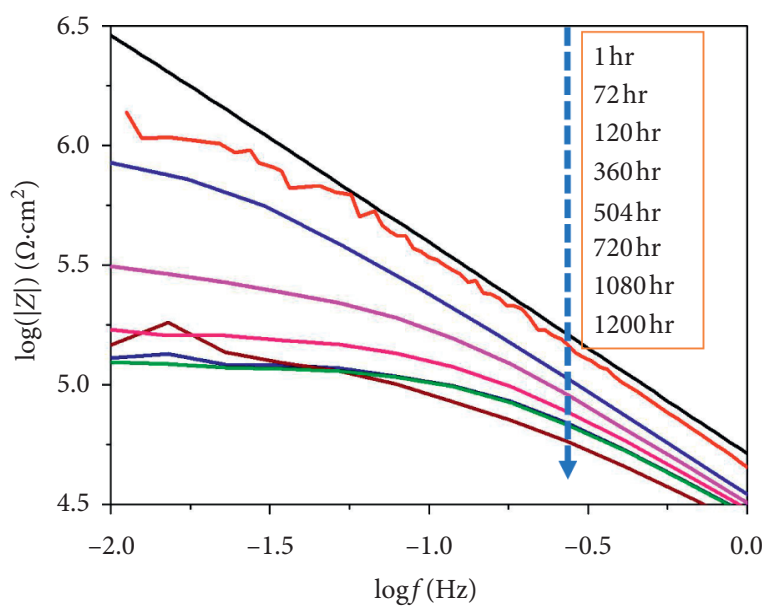

(d)

Figure 8: Impedance modulus plots of ( $a$ and $b$ ) CeLDH, ( $c$ and d) CeLDH-H with respective enlarged images for clear depiction at various immersion times, from $1 \mathrm{~h}$ to $1200 \mathrm{~h}$.

anodic film layers and active role of cerium in providing a sort of healing effect thanks to its recognized effect as a corrosion inhibitor.

To further analyze the properties of the developed thin films containing Ce, the EIS data were fitting by using the "ZSimpwin" software [28]. Two different circuits were employed to investigate the EIS experimental dataset. At an early stage of immersion (1-120 h), two time constants were observed: one located in the high-frequency range (around $10^{4} \mathrm{~Hz}$ ) and the other in the low-frequency range (around $10^{-1} \mathrm{~Hz}$ ). According to the literature, it seems quite well established that the former can be associated with the response of the porous anodic oxide/LDH layer covering the metal [29-37]. Conversely, the attribution of the latter is not univocal and different interpretations can be found in the literature. Hoar and Wood [35] and, later, Mansfeld [36] ascribed the middle-low frequency time constant to the properties of the barrier layer between the bottom of the pores and the metal oxide. Similarly, Huang et al. [31, 32] interpreted the middle-low frequency relaxation process as the contribution of the inner barrier layer of the anodic oxide. On the other hand, Zhu et al. [30] described the lowfrequency loop as the superimposition of the contribution of the inner barrier oxide and the charge transfer process: a polarization resistance and a constant phase element (CPE) to account for the electrical double layer and barrier layer were used to fit the relaxation process. Similarly, Usman et al. [29] associated the low-frequency time constant with the charge transfer processes related to the barrier layer and, for prolonged immersion time, with the corrosion of the substrate. For the sample under investigation, at the beginning of the immersion the $|Z|_{0.01}$ value is relatively high, thus suggesting that the low-frequency response can be attributed to the superimposition of the contribution of the inner barrier oxide and the charge transfer process. A contribution associated with the corrosion process will be introduced for longer immersion time. A similar approach has been employed by other authors [37].

The circuit depicted in Figure 10(a) was employed to fit the EIS dataset at an early stage of immersion (1-120 h): $R_{\mathrm{s}}$ stands for the electrolyte resistance; $R_{\mathrm{LDH}}$ and $\mathrm{CPE}_{\mathrm{LDH}}$ refer to the conductive paths and the dielectric properties of the 


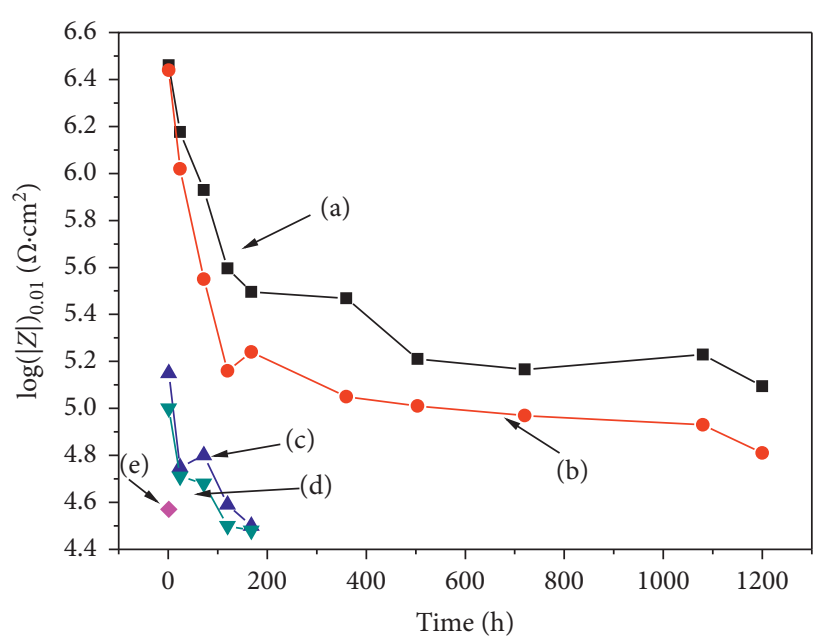

FIgURE 9: Impedance modulus at $0.01 \mathrm{~Hz}$ at various immersion times: (a) CeLDH, (b) CeLDH-H, (c) LDH, (d) LDH-H, and (e) anodic AA6082.

porous anodization layer $+\mathrm{LDH}$ coating, respectively; $R_{\mathrm{b}}$ accounts for the resistance of the barrier oxide, while $\mathrm{CPE}_{\mathrm{b}}$ refers to the dielectric response of the electrical double layer and barrier layer [30].

Constant phase element (CPE) was employed instead of pure capacitances, according to the general expression, i.e., $Z_{\mathrm{CPE}}=1 /(Q(\omega j))^{\alpha}$. CPEs are recognized to be a flexible fitting parameter to account for capacitance distributions that originated from surface roughness and heterogeneities, electrode porosity, variation of coating composition, nonuniform potential, and current distribution [38].

In the second stage of immersion (168-1200 h), the phase peak in the low-frequency range is no more symmetrical and cannot be properly fitted by means of the e. e. c. depicted in Figure 10(a). Furthermore, a significant decrease of the impedance modulus in the low-frequency domain is observed (see Figure 9). According to other authors [37] from $168 \mathrm{~h}$ of immersion in the saline solution, a contribution of the corrosion process is introduced in the e. e. c. employed to fit the experimental EIS dataset (Figure 10(b)). Notice that an additional time constant to account for the Faradic process is introduced. In particular, $R_{\mathrm{s}}$ stands for the electrolyte resistance; $R_{\mathrm{LDH}}$ and $\mathrm{CPE}_{\mathrm{LDH}}$ refer to the conductive paths and the dielectric properties of the porous anodization layer $+\mathrm{LDH}$ coating, respectively; $R_{\mathrm{b}}$ accounts for the resistance of the barrier oxide, while $\mathrm{CPE}_{\mathrm{b}}$ refers to its dielectric response; $R_{\mathrm{ct}}$ stands for the charge transfer resistance while $\mathrm{CPE}_{\mathrm{dl}}$ refers to the dielectric response of the doublelayer capacitance. The parameter obtained by means of the fitting of the raw EIS data is reported in Tables 2 and 3.

As far as the fitting parameters related to the porous oxide/LDH layer are concerned $\left(Q_{\mathrm{LDH}}, R_{\mathrm{LDH}}, \alpha_{\mathrm{LDH}}\right)$, notice that the resistances of porous layer are lower than the associated barrier layer resistance. This is in accordance with previous studies which explained this finding with the higher conduction in the sealed pores compared to the barrier layers [37]. The $Q_{\mathrm{LDH}}$ values are quite scattered, probably due to the permeable structure of the porous anodic layer as well as the LDH layer. The corresponding values of the exponent of the CPE, $\alpha_{\mathrm{LDH}}$, are in the 0.58-0.84 range during immersion time. This parameter is recognized to be dependent on the fractal nature of the surface (affected by roughness and porosity) [38], on the roughness of the interphase [39], and on heterogeneities of the electrode surface [40]. Within this framework, the obtained data suggest a quite significant evolution of the surface roughness and porosity of the porous anodic oxide/LDH layer during immersion time. Partial dissolution of the porous anodic oxide and precipitation of insoluble compound over the surface of the electrodes are likely to occur and would explain the $\alpha_{\mathrm{LDH}}$ values (which are quite far from unity). The surface conditions of the electrodes after the immersion will be investigated at the end of this section to further support this hypothesis. On the other hand, given such values of $\alpha_{\mathrm{LDH}}, Q_{\mathrm{LDH}}$ cannot be clearly ascribed to a specific physical property. $Q_{\mathrm{LDH}}$ is believed to account for the dielectric properties of the porous anodic oxide/LDH layer but a more defined description is not possible.

On the other hand, $R_{\mathrm{b}}$ values, suggesting the barrier properties of the layer, have shown significant resistance values and demonstrate improved barrier properties for CeLDH compared to the CeLDH-H. It can also be seen that $R_{\mathrm{b}}$ values for CeLDH show a decrease from $2.2 \cdot 10^{7} \Omega \cdot \mathrm{cm}^{2}$ and $1.5 \cdot 10^{6} \Omega \cdot \mathrm{cm}^{2}$ to $3.8 \cdot 10^{5} \Omega \cdot \mathrm{cm}^{2}$ and $4.7 \cdot 10^{3} \Omega \cdot \mathrm{cm}^{2}$ for $\mathrm{CeLDH}$ and $\mathrm{CeLDH}-\mathrm{H}$, respectively, with the immersion of $1 \mathrm{hr}$ to $1200 \mathrm{hr}$ in $\mathrm{NaCl}$ solution. These findings suggest that the hot water sealing treatment seems not beneficial to further improve the barrier properties of the CeLDH coatings. The $Q_{\mathrm{b}}$ values, although slightly scattering in the first days of immersion, are almost stable during immersion time. The numerical values of the CeLDH and CeLDH-H sample are comparable: this suggests that the thickness of the barrier layer for the two different samples is similar. As far as the exponent of the CPE, $\alpha_{\mathrm{b}}$ is concerned, it ranges from 0.66 to 0.89 for both sealed and unsealed samples. These values suggest that the barrier oxide is heterogenous [40]. The sealing was supposed to be able to "plug" the flaws present in barrier layers, thus increasing its homogeneity [37]. However, no relevant differences are observed between sealed and unsealed samples in our case. This finding further supports the reduced beneficial effect of the hot water sealing for the investigated samples.

Similarly, $R_{\mathrm{ct}}$ values indicate that the extent of the corrosion process occurring on CeLDH-H is more pronounced compared to CeLDH. In fact, the $R_{\mathrm{ct}}$, which is inversely proportional to corrosion rate, is a parameter representing the resistance of the electron transfer across the metal surface [41]. It is recognized that the higher $R_{\mathrm{ct}}$ is, the more difficult the corrosion reaction is and hence the lower the corrosion rate is [28].

XRD pattern of the investigated samples after $1200 \mathrm{~h}$ of immersion in the electrolyte has been collected in order to investigate the different species developed on the surface upon immersion in the saline solution. XRD diffraction parameters of $\mathrm{CeLDH}$ and CeLDH-H after $1200 \mathrm{hrs}$ of immersions are shown in Figure 11 The X-ray diffraction 


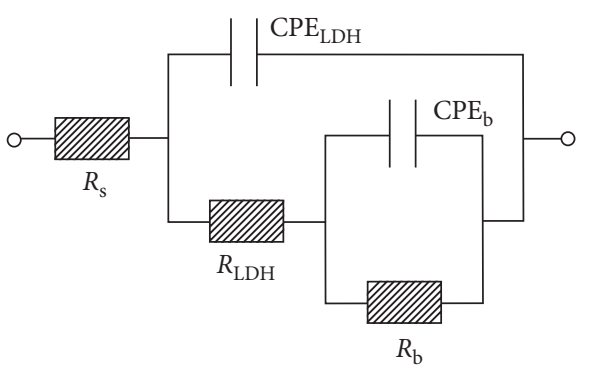

(a)

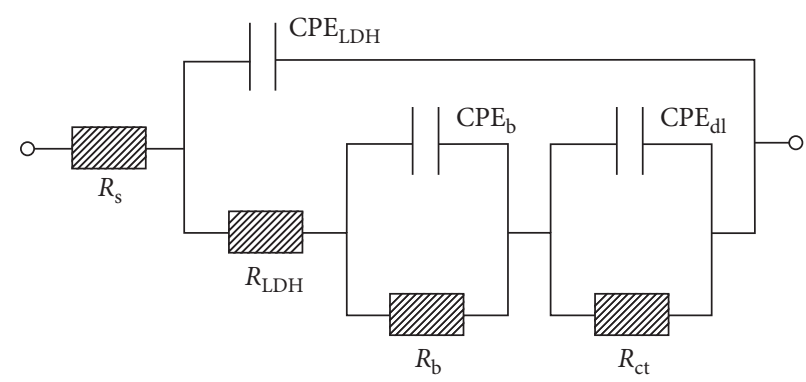

(b)

FIGURE 10: Electrical equivalent circuits employed to fit the EIS experimental dataset: (a) at the early stage of immersion (1-120 h) and (b) for prolonged immersion $(168-1200 \mathrm{~h})$ in $0.1 \mathrm{M} \mathrm{NaCl}$.

TABLE 2: Results of the EIS fittings of CeLDH.

\begin{tabular}{|c|c|c|c|c|c|c|c|c|c|}
\hline & $Q_{\mathrm{LDH}}\left(\Omega^{-1} \cdot \mathrm{cm}^{-2} \cdot \mathrm{s}^{\alpha}\right)$ & $R_{\mathrm{LDH}}\left(\Omega \cdot \mathrm{cm}^{2}\right)$ & $\alpha_{\mathrm{LDH}}$ & $Q_{\mathrm{b}}\left(\Omega^{-1} \cdot \mathrm{cm}^{-2} \cdot \mathrm{s}^{\alpha}\right)$ & $R_{\mathrm{b}}\left(\Omega \cdot \mathrm{cm}^{2}\right)$ & $\alpha_{\mathrm{dl}}$ & $Q_{\mathrm{dl}}\left(\Omega^{-1} \cdot \mathrm{cm}^{-2} \cdot \mathrm{s}^{\alpha}\right)$ & $R_{\mathrm{ct}}\left(\Omega \cdot \mathrm{cm}^{2}\right)$ & $\alpha_{\mathrm{dl}}$ \\
\hline 1 & $3.7 \times 10^{-6}$ & $4.3 \times 10^{3}$ & 0.82 & $6.1 \times 10^{-6}$ & $2.2 \times 10^{7}$ & 0.78 & - & - & - \\
\hline 24 & $3.5 \times 10^{-6}$ & $1.9 \times 10^{2}$ & 0.86 & $6.9 \times 10^{-5}$ & $2.0 \times 10^{7}$ & 0.89 & - & - & - \\
\hline 72 & $7.4 \times 10^{-6}$ & $4.4 \times 10^{2}$ & 0.78 & $6.9 \times 10^{-5}$ & $3.6 \times 10^{6}$ & 0.71 & - & - & - \\
\hline 120 & $2.2 \times 10^{-6}$ & $5.6 \times 10^{2}$ & 0.67 & $5.8 \times 10^{-6}$ & $9.2 \times 10^{5}$ & 0.78 & - & - & - \\
\hline 168 & $3.9 \times 10^{-6}$ & $3.0 \times 10^{2}$ & 0.77 & $5.9 \times 10^{-6}$ & $2.0 \times 10^{6}$ & 0.88 & $6.1 \times 10^{-6}$ & $8.7 \times 10^{8}$ & 0.74 \\
\hline 360 & $2.5 \times 10^{-4}$ & $6.9 \times 10^{2}$ & 0.84 & $8.2 \times 10^{-6}$ & $6.0 \times 10^{6}$ & 0.66 & $6.5 \times 10^{-6}$ & $7.4 \times 10^{8}$ & 0.77 \\
\hline 720 & $3.7 \times 10^{-7}$ & $4.9 \times 10^{2}$ & 0.81 & $3.4 \times 10^{-6}$ & $4.7 \times 10^{5}$ & 0.69 & $6.8 \times 10^{-6}$ & $5.2 \times 10^{7}$ & 0.79 \\
\hline 1080 & $7.2 \times 10^{-8}$ & $3.4 \times 10^{2}$ & 0.79 & $8.7 \times 10^{-6}$ & $1.2 \times 10^{5}$ & 0.77 & $3.6 \times 10^{-6}$ & $3.9 \times 10^{7}$ & 0.69 \\
\hline 1200 & $1.2 \times 10^{-7}$ & $8.3 \times 10^{1}$ & 0.78 & $4.5 \times 10^{-6}$ & $3.8 \times 10^{5}$ & 0.67 & $3.9 \times 10^{-6}$ & $7.5 \times 10^{7}$ & 0.71 \\
\hline
\end{tabular}

TABLE 3: Results of the EIS fittings of CeLDH-H.

\begin{tabular}{|c|c|c|c|c|c|c|c|c|c|}
\hline & $Q_{\mathrm{LDH}}\left(\Omega^{-1} \cdot \mathrm{cm}^{-2} \cdot \mathrm{s}^{\alpha}\right)$ & $R_{\mathrm{LDH}}\left(\Omega \cdot \mathrm{cm}^{2}\right)$ & $\alpha_{\mathrm{LDH}}$ & $Q_{\mathrm{b}}\left(\Omega^{-1} \cdot \mathrm{cm}^{-2} \cdot \mathrm{s}^{\alpha}\right)$ & $R_{\mathrm{b}}\left(\Omega \cdot \mathrm{cm}^{2}\right)$ & $\alpha_{\mathrm{dl}}$ & $Q_{\mathrm{dl}}\left(\Omega^{-1} \cdot \mathrm{cm}^{-2} \cdot \mathrm{s}^{\alpha}\right)$ & $R_{\mathrm{ct}}\left(\Omega \cdot \mathrm{cm}^{2}\right)$ & $\alpha_{\mathrm{dl}}$ \\
\hline 1 & $1.5 \times 10^{-7}$ & $1.3 \times 10^{3}$ & 0.82 & $5.7 \times 10^{-6}$ & $1.5 \times 10^{6}$ & 0.78 & - & - & - \\
\hline 3 & $5.6 \times 10^{-8}$ & $8.1 \times 10^{2}$ & 0.82 & $5.4 \times 10^{-6}$ & $5.4 \times 10^{6}$ & 0.87 & - & - & - \\
\hline 5 & $4.1 \times 10^{-6}$ & $7.8 \times 10^{2}$ & 0.84 & $2.7 \times 10^{-8}$ & $4.4 \times 10^{5}$ & 0.85 & - & - & - \\
\hline 24 & $2.6 \times 10^{-6}$ & $7.4 \times 10^{2}$ & 0.64 & $4.2 \times 10^{-6}$ & $5.5 \times 10^{4}$ & 0.89 & - & - & - \\
\hline 72 & $7.4 \times 10^{-6}$ & $4.4 \times 10^{1}$ & 0.84 & $6.9 \times 10^{-5}$ & $4.6 \times 10^{4}$ & 0.71 & & & \\
\hline 120 & $2.4 \times 10^{-7}$ & $5.4 \times 10^{1}$ & 0.88 & $4.1 \times 10^{-6}$ & $1.1 \times 10^{5}$ & 0.78 & & & \\
\hline 168 & $3.7 \times 10^{-7}$ & $3.0 \times 10^{1}$ & 0.76 & $1.8 \times 10^{-6}$ & $2.5 \times 10^{5}$ & 0.81 & $4.8 \times 10^{-6}$ & $8.8 \times 10^{7}$ & 0.88 \\
\hline 360 & $7.2 \times 10^{-7}$ & $4.1 \times 10^{2}$ & 0.78 & $8.2 \times 10^{-6}$ & $9.7 \times 10^{5}$ & 0.89 & $6.1 \times 10^{-6}$ & $7.8 \times 10^{7}$ & 0.89 \\
\hline 720 & $3.5 \times 10^{-6}$ & $6.1 \times 10^{1}$ & 0.58 & $3.4 \times 10^{-6}$ & $7.0 \times 10^{5}$ & 0.87 & $6.5 \times 10^{-6}$ & $4.7 \times 10^{6}$ & 0.78 \\
\hline 1080 & $3.5 \times 10^{-6}$ & $7.9 \times 10^{1}$ & 0.57 & $8.7 \times 10^{-6}$ & $6.0 \times 10^{3}$ & 0.66 & $6.8 \times 10^{-6}$ & $5.8 \times 10^{6}$ & 0.79 \\
\hline 1200 & $3.5 \times 10^{-6}$ & $4.3 \times 10^{1}$ & 0.77 & $4.5 \times 10^{-6}$ & $4.7 \times 10^{3}$ & 0.76 & $1.2 \times 10^{-6}$ & $6.3 \times 10^{5}$ & 0.77 \\
\hline
\end{tabular}

measurements after contact with $0.1 \mathrm{M} \mathrm{NaCl}$ solution lead to similar characteristics peaks of LDHs with similar pattern with some additional peaks around 2 theta values of $28.6^{\circ}$, $33.5^{\circ}, 48^{\circ}$, and $56.2^{\circ}$ which depicted the formation of $\mathrm{CeO}_{2}$ and $\mathrm{Ce}(\mathrm{OH})_{3}$. The low intense cerium oxide/hydroxide peaks support the presence of crystalline cerium oxide in the LDH layer. Considering that these compounds were not found before the exposure in the electrolyte, it is likely that a release of Ce occurred from the amorphous domains in the anodic oxide/LDH layer. Ce entered the solution from the LDH structure and the consequent precipitated over cathodic sites upon reaction with $\mathrm{OH}^{-}$species. This mechanism is believed to be responsible for the anticorrosion properties of LDHs due to the inhibition of the cathodic reaction provided by the precipitated compounds (mixed cerium oxide/hydroxides). Matter et al. [21] previously investigated the cerium inhibition effect and reported that $\mathrm{Ce}$ (III) attributes better inhibitive ability than $\mathrm{Ce}(\mathrm{IV})$ and thus $\mathrm{Ce}$ (III) addition on the LDHs is likely to be responsible for a sort of self-healing effect by forming $\mathrm{Ce}(\mathrm{OH})_{3} / \mathrm{CeO}_{2}$ on protective film degradation. The corrosion protection ability of cerium salts is already well reported in various works, where the inhibiting mechanism is recognized to involve the impediment of the cathodic oxygen reduction reaction due to the formation of cerium hydroxides/oxides [42-44].

The SEM images of CeLDH after treatment with $0.1 \mathrm{M}$ $\mathrm{NaCl}$ solution after 360,720 , and 1200 hrs are shown in Figure 12, where results indicated the good intactness and stability of the structure after $360 \mathrm{hrs}$ of immersion and 


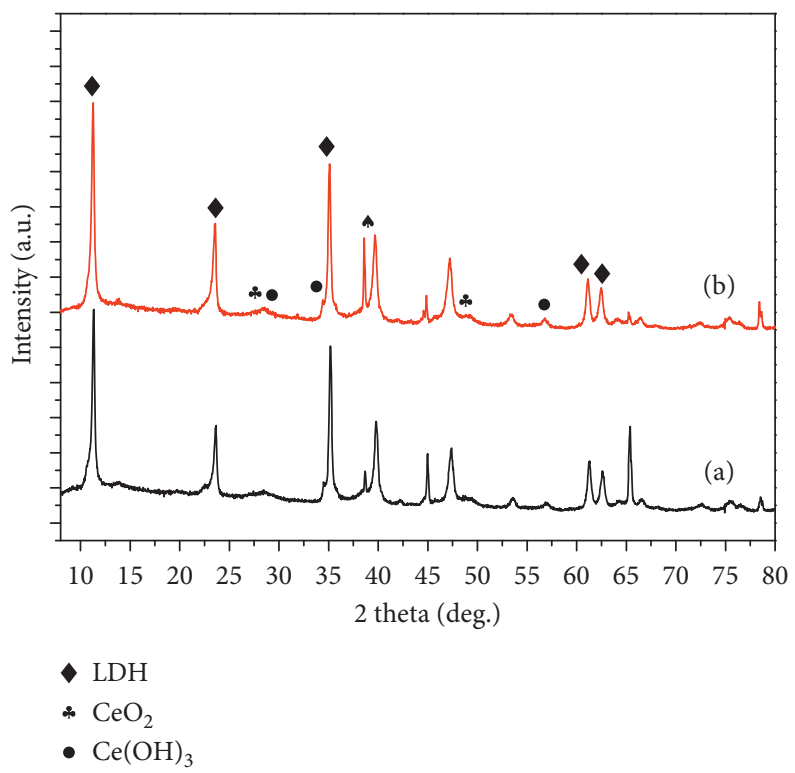

FIgURE 11: XRD patterns after $1200 \mathrm{hrs}$ of immersion in $0.1 \mathrm{M} \mathrm{NaCl}$ solution: (a) CeLDH-H, (b) CeLDH.

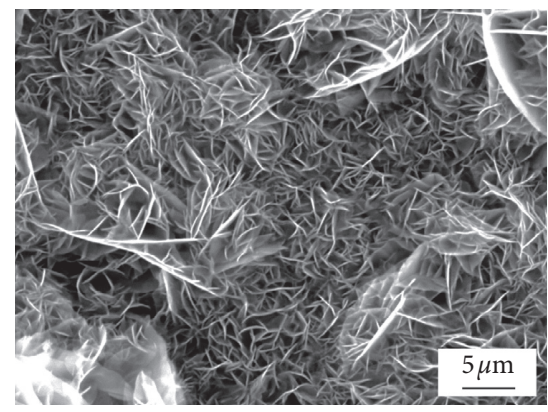

(a)

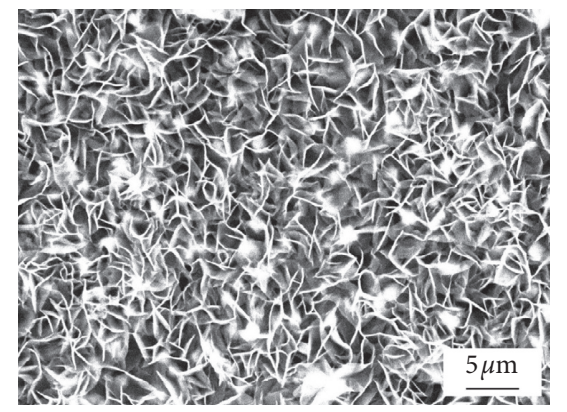

(b)

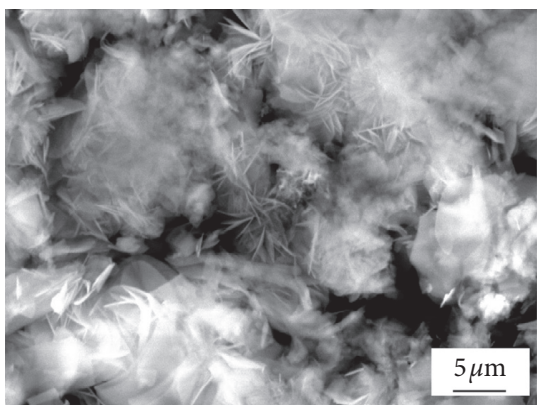

(c)

Figure 12: SEM images after (a) $360 \mathrm{hrs}$ of immersion, (b) $720 \mathrm{hrs}$ of immersion, (c) $1200 \mathrm{hrs}$ of immersion in $0.1 \mathrm{M} \mathrm{NaCl}$ solution.

similarly after $720 \mathrm{hrs}$ of immersion. However, corrosion products seem to precipitate over the surface after $720 \mathrm{~h}$ of immersion. After $1200 \mathrm{~h}$ of immersion, the partial destruction of regular platelet structure can be seen and results in an expansion of platelet structure with the accumulation of corrosion products on the surface. However, XRD analysis confirms the intactness of LDH geometry after $1200 \mathrm{~h}$ immersion in $0.1 \mathrm{M} \mathrm{NaCl}$ solution. The observation of LDH geometry is well correlated with the EIS findings which suggest a limited degradation extent of the protective layers.

\section{Conclusion}

Ce based MgAl-LDH conversion films were developed by a single-step in situ growth method on the anodized AA6082 surface. The sealing effect of CeMgAl-LDHs precursors on the anodized porous network and corresponding barrier effect in terms of long-term corrosion resistance behavior and structural evaluation is discussed. The introduction of cerium directly on the anodized porous network (CeLDH) has shown improved corrosion resistance properties, compared to the $\mathrm{CeLDH}-\mathrm{H}$ which were grown on "hot water-sealed" anodized surface. The findings demonstrated that CeLDH provided comparatively better active and passive corrosion protection than other developed specimens. The evaluation of coating parameters defined the corrosion mechanism for LDHs and their behaviour on long-term stability against corrosive species. The CeLDH was found intact after $360 \mathrm{hrs}$ of immersion and slightly corroded after $760 \mathrm{hrs}$ of immersion and provided stable longer period protection $(1200 \mathrm{hrs})$ for the underlying AA6082 substrate. Ce oxides/hydroxides were found on the LDH surface after prolonged exposure to the chloride solution. This finding suggested the capability of the film to release cerium cations to the environment and their capability to precipitate in correspondence of the cathodic sites upon reaction with $\mathrm{OH}^{-}$species. The CeLDH developed directly on the porous anodic film can be potentially used for further functionalization for the enhanced protection of aluminum alloys. 


\section{Data Availability}

Data are available on request from Muhammad Ahsan Iqbal (University of Trento, Department of Industrial Engineering, via Sommarive n. 9, 38123 Trento, Italy, muhammadahsan.iqbal@unitn.it).

\section{Conflicts of Interest}

The authors declare no conflicts of interest regarding the publication of this paper.

\section{References}

[1] C. Zhang, X. Luo, X. Pan, L. Liao, X. Wu, and Y. Liu, "Selfhealing Li-Al layered double hydroxide conversion coating modified with aspartic acid for $6 \mathrm{~N} 01 \mathrm{Al}$ alloy," Applied Surface Science, vol. 394, pp. 275-281, 2017.

[2] Y. Wang and D. Zhang, "Synthesis, characterization, and controlled release anticorrosion behavior of benzoate intercalated Zn-Al layered double hydroxides," Material Research Bulletin, vol. 46, no. 11, pp. 1963-1968, 2011.

[3] T. Yan, S. Xu, Q. Peng et al., "Self-healing of layered double hydroxide film by dissolution/recrystallization for corrosion protection of aluminum," Journal of The Electrochemical Society, vol. 160, no. 10, pp. C480-C486, 2013.

[4] M. A. Iqbal and M. Fedel, "Effect of synthesis conditions on the controlled growth of MgAl-LDH corrosion resistance film: structure and corrosion resistance properties," Coatings, vol. 9, no. 1, p. 30, 2019.

[5] M. A. Iqbal and M. Fedel, "Effect of operating parameters on the structural growth of $\mathrm{ZnAl}$ layered double hydroxide on AA6082 and corresponding corrosion resistance properties," Journal of Coatings Technology and Research, vol. 16, no. 5, pp. 1423-1433, 2019.

[6] M. A. Iqbal, L. Sun, A. M. LaChance, H. Ding, and M. Fedel, "In situ growth of a CaAl- $\mathrm{NO}_{3-}$-layered double hydroxide film directly on an aluminum alloy for corrosion resistance," Dalton Transactions, vol. 49, no. 13, pp. 3956-3964, 2020.

[7] F. Zhang, C.-L. Zhang, L. Song, R.-C. Zeng, L.-Y. Cui, and H.-Z. Cui, "Corrosion resistance of superhydrophobic mg-al layered double hydroxide coatings on aluminum alloys," Acta Metallurgica Sinica (English Letters), vol. 28, no. 11, pp. 1373-1381, 2015.

[8] I. Imanieh and A. Afshar, "Corrosion protection of aluminum by smart coatings containing layered double hydroxide (LDH) nanocontainers," Journal of Materials Research and Technology, vol. 8, no. 3, pp. 3004-3023, 2019.

[9] M. Kaseem and Y. G. Ko, "A novel composite system composed of zirconia and LDHs film grown on plasma electrolysis coating: toward a stable smart coating," Ultrasonics Sonochemistry, vol. 49, pp. 316-324, 2018.

[10] T. Stimpfling, F. Leroux, and H. Hintze-Bruening, "Unraveling EDTA corrosion inhibition when interleaved into layered double hydroxide epoxy filler system coated onto aluminum AA 2024," Applied Clay Science, vol. 83-84, pp. 32-41, 2013.

[11] H. Chen, F. Zhang, S. Fu, and X. Duan, "In situ microstructure control of oriented layered double hydroxide monolayer films with curved hexagonal crystals as superhydrophobic materials," Advanced Materials, vol. 18, no. 23, pp. 3089-3093, 2006.

[12] B. Kuznetsov, M. Serdechnova, J. Tedim et al., "Sealing of tartaric sulfuric (TSA) anodized AA2024 with nanostructured
LDH layers," RSC Advances, vol. 6, no. 17, pp. 13942-13952, 2016.

[13] F. Kovanda, P. Mašátova, P. Novotná, and K. Jirátova, "The formation of layered double hydroxides on alumina surface in aqueous solutions containing divalent metal cations," Clays and Clay Minerals, vol. 57, no. 4, pp. 425-432, 2009.

[14] L. Wang, B. Li, X. Zhao, C. Chen, and J. Cao, "Effect of rare earth ions on the properties of composites composed of ethylene vinyl acetate copolymer and layered double hydroxides," PLoS One, vol. 7, no. 6, Article ID e37781, 2012.

[15] van de Sanden, R. J. Severens, J. Bastiaanssen, and D. C. Schram, "High-quality a-Si:H growth at high rate using an expanding thermal plasma," Surface and Coatings Technology, vol. 97, no. 1-3, pp. 719-722, 1997.

[16] J. Liu, Y. Zhang, M. Yu, S. Li, B. Xue, and X. Yin, "Influence of embedded $\mathrm{ZnAlCe}-\mathrm{NO}_{3}$ - layered double hydroxides on the anticorrosion properties of sol-gel coatings for aluminum alloy," Progress in Organic Coatings, vol. 81, no. 3, pp. 93-100, 2015.

[17] Y. Wang, W. Peng, L. Liu, F. Gao, and M. Li, "The electrochemical determination of 1-cysteine at a Ce-doped Mg-Al layered double hydroxide modified glassy carbon electrode," Electrochimica Acta, vol. 70, pp. 193-198, 2012.

[18] Y. Zhang, Y. Li, Y. Ren, H. Wang, and F. Chen, "Doubledoped LDH films on aluminum alloys for active protection," Materials Letters, vol. 192, pp. 33-35, 2017.

[19] G. Zhang, L. Wu, A. Tang et al., "Active corrosion protection by a smart coating based on a MgAl-layered double hydroxide on a cerium-modified plasma electrolytic oxidation coating on Mg alloy AZ31," Corrosion Science, vol. 139, pp. 370-382, 2018.

[20] J. Carneiro, A. F. Caetano, A. Kuznetsova et al., "Polyelectrolyte-modified layered double hydroxide nanocontainers as vehicles for combined inhibitors," RSC Advances, vol. 5, no. 50, pp. 39916-39929, 2015.

[21] E. A. Matter, S. Kozhukharov, M. Machkova, and V. Kozhukharov, "Comparison between the inhibition efficiencies of Ce (III) and Ce (IV) ammonium nitrates against corrosion of AA2024 aluminum alloy in solutions of low chloride concentration," Corrosion Science, vol. 62, pp. 22-33, 2012.

[22] M. Machkova, E. A. Matter, S. Kozhukharov, and V. Kozhukharov, "Effect of the anionic part of various Ce (III) salts on the corrosion inhibition efficiency of AA2024 aluminium alloy," Corrosion Science, vol. 69, no. 3, pp. 396-405, 2013.

[23] Y. Liu, T. Yu, R. Cai, Y. Li, W. Yang, and J. Caro, "One-pot synthesis of $\mathrm{NiAl}-\mathrm{CO}_{3} \mathrm{LDH}$ anti-corrosion coatings from $\mathrm{CO}_{2}$-saturated precursors," RSC Advances, vol. 5, no. 37, pp. 29552-29557, 2015.

[24] N. C. Rosero-Navarro, S. A. Pellice, A. Durán, and M. Aparicio, "Effects of Ce-containing sol-gel coatings reinforced with $\mathrm{SiO}_{2}$ nanoparticles on the protection of AA2024," Corrosion Science, vol. 50, no. 5, pp. 1283-1291, 2008.

[25] C. Ke, Y. Wu, Y. Qiu, J. Duan, N. Birbilis, and X.-B. Chen, "Influence of surface chemistry on the formation of crystalline hydroxide coatings on $\mathrm{Mg}$ alloys in liquid water and steam systems," Corrosion Science, vol. 113, pp. 145-159, 2016.

[26] B. Davó and J. J. de Damborenea, "Use of rare earth salts as electrochemical corrosion inhibitors for an Al-Li-Cu (8090) alloy in 3.56\% NaCl," Electrochimica Acta, vol. 49, no. 27, pp. 4957-4965, 2004. 
[27] F. Zhang, Z.-G. Liu, R.-C. Zeng et al., "Corrosion resistance of Mg-Al-LDH coating on magnesium alloy AZ31," Surface and Coatings Technology, vol. 258, pp. 1152-1158, 2014.

[28] B. Dou, Y. Wang, T. Zhang et al., "Growth behaviors of layered double hydroxide on microarc oxidation film and anti-corrosion performances of the composite film," Journal of The Electrochemical Society, vol. 163, no. 14, pp. C917C927, 2016.

[29] B. J. Usman, F. Scenini, and M. Curioni, "Corrosion testing of anodized aerospace alloys: comparison between immersion and salt spray testing using electrochemical impedance spectroscopy," Journal of The Electrochemical Society, vol. 167, no. 4, Article ID 041505, 2020.

[30] B. Zhu, M. Fedel, N.-E. Andersson, P. Leisner, F. Deflorian, and C. Zanella, "Effect of Si content and morphology on corrosion resistance of anodized cast Al-Si alloys," Journal of the Electrochemical Society, vol. 164, no. 7, pp. C435-C441, 2017.

[31] Y. Huang, H. Shih, J. Daugherty, and F. Mansfeld, "Evaluation of the properties of anodized aluminum 6061 subjected to thermal cycling treatment using electrochemical impedance spectroscopy (EIS)," Corrosion Science, vol. 51, no. 10, pp. 2493-2501, 2009.

[32] Y. Huang, H. Shih, H. Huang et al., "Evaluation of the corrosion resistance of anodized aluminum 6061 using electrochemical impedance spectroscopy (EIS)," Corrosion Science, vol. 50, no. 12, pp. 3569-3575, 2008.

[33] D. Veys-Renaux, R. Drevet, C. Petitjean, L. Aranda, N. David, and P. Berthod, "Electrochemical behavior of $\mathrm{CoSb}_{3}$ in sulfuric and oxalic acids over the potential range 0 to $40 \mathrm{~V}$," Journal of Solid State Electrochemistry, vol. 22, no. 9, pp. 2821-2828, 2018.

[34] F. Zhang, C. Örnek, J. O. Nilsson, and J. Pan, "Anodisation of aluminium alloy AA7075-influence of intermetallic particles on anodic oxide growth," Corrosion Science, vol. 164, Article ID 108319, 2020.

[35] T. P. Hoar and G. C. Wood, "On the assessment of sealing of anodic oxide films on aluminium," Transactions of the IMF, vol. 37 , no. 1, pp. 7-10, 1960.

[36] F. Mansfeld, "Analysis and interpretation of EIS data for metals and alloys," Solartron Technical Report No. 26, University of Southern California, Los Angeles, CA, USA, 1999.

[37] V. Moutarlier, M. P. Gigandet, B. Normand, and J. Pagetti, "EIS characterisation of anodic films formed on 2024 aluminium alloy, in sulphuric acid containing molybdate or permanganate species," Corrosion Science, vol. 47, no. 4, pp. 937-951, 2005.

[38] J.-B. Jorcin, M. E. Orazem, N. Pébère, and B. Tribollet, "CPE analysis by local electrochemical impedance spectroscopy," Electrochimica Acta, vol. 51, no. 8-9, pp. 1473-1479, 2006.

[39] J. H. Scofield, "Comment on "Fractal model for the ac response of a rough interface," Physical Review Letters, vol. 56, no. 3, p. $268,1986$.

[40] L. Bouchama, N. Azzouz, N. Boukmouche, J. P. Chopart, A. L. Daltin, and Y. Bouznit, "Enhancing aluminum corrosion resistance by two-step anodizing process," Surface and Coatings Technology, vol. 235, pp. 676-684, 2013.

[41] D. Zhu and W. J. Van Ooij, "Corrosion protection of AA 2024-T3 by bis-[3-(triethoxysilyl) propyl]tetrasulfide in sodium chloride solution," Corrosion Science, vol. 45, no. 10, pp. 2177-2197, 2003.

[42] D. Raps, T. Hack, J. Wehr et al., "Electrochemical study of inhibitor-containing organic-inorganic hybrid coatings on
AA2024," Corrosion Science, vol. 51, no. 5, pp. 1012-1021, 2009.

[43] H. Shi, E.-H. Han, F. Liu, and S. Kallip, "Protection of 2024-T3 aluminium alloy by corrosion resistant phytic acid conversion coating," Applied Surface Science, vol. 280, pp. 325-331, 2013.

[44] M. A. Arenas and J. J. De Damborenea, "Growth mechanisms of cerium layers on galvanised steel," Electrochimica Acta, vol. 48, no. 24, pp. 3693-3698, 2003. 